\title{
Planar Monopoles with Different Radiator Shapes for UWB Body-Centric Wireless Communications
}

\author{
Y. Y. Sun, S. W. Cheung, and T. I. Yuk \\ Department of Electrical and Electronic Engineering, The University of Hong Kong, Hong Kong \\ Correspondence should be addressed to Y. Y. Sun; yysun@eee.hku.hk
}

Received 27 September 2012; Revised 30 May 2013; Accepted 31 May 2013

Academic Editor: Karim Kabalan

Copyright (C) 2013 Y. Y. Sun et al. This is an open access article distributed under the Creative Commons Attribution License, which permits unrestricted use, distribution, and reproduction in any medium, provided the original work is properly cited.

\begin{abstract}
This paper presents a study on the performances of a group of planar monopoles using radiators of different shapes, such as triangle, rectangle, square, annual ring, circle, horizontal ellipse, vertical ellipse, pentagon, and hexagon, for ultra-wideband (UWB) bodycentric wireless communications. The planar monopoles have the radiators with microstrip-fed line printed on one side of the substrate and a ground plane on the other side. Simulation studies show that, among these monopoles, the horizontal elliptical, vertical elliptical, and hexagonal monopoles have better overall performances in terms of bandwidth, gain, efficiency, and radiation pattern in free space. A solid-body phantom mimicking human tissue is used for studies of these three monopoles for body-centric communications. Simulated and measured results of these monopoles on the phantom show that the horizontal elliptical monopole achieves the widest impedance bandwidths, highest average peak gain and efficiency, least path loss, best fidelity, and good radiation pattern, making it a good candidate for UWB body-centric wireless communications.
\end{abstract}

\section{Introduction}

Ultra-wideband (UWB) technology [1], due to the advantages of low cost, low complexity, low spectral power density, high precision ranging, low interference, and extremely high data rates, has attracted much attention [2-6]. One of the most promising areas in UWB applications is body-centric wireless communications where various sensors are connected together by UWB devices which have to be low power, low profile, and unobtrusive to the human body $[7,8]$. However, the electrical properties of human body make the design of UWB antennas for body-centric wireless communications very complicated. Several fundamental requirements such as wide impedance bandwidth, small size and low profile, good on-body propagation, high front-to-back ratio, and good radiation characteristics in the proximity of the body need to be fulfilled [7-12]. Some practical applications of bodycentric wireless communications systems have been studied. In [13], a body-centric wireless communication equipment, SenseWear Pro2 Armband, was studied for health monitoring. It was worn on the arms for up to two weeks continuously and allowed calculation of energy expenditure and quantification of metabolic physical activity. In [14], a wearable textile antenna integrated in protective garments for firefighters was presented.

Comparison of different UWB antennas for body communications has been studied before since 2005 [9, 15-17]. In [10], two types of UWB antennas, printed horn-shaped selfcomplementary antenna (HSCA) and planar inverted cone antenna (PICA), were compared for UWB on-body channels. In [15], the characteristics of four planar dipoles were studied and compared based on the design consideration of UWB antennas. In [16], a directional UWB antenna with an added reflector element was designed and compared to an omnidirectional UWB monopole antenna with a circular radiator for wireless body area network applications. All these works were done in the quite early age of body communications and only two different antennas were studied and compared in these studies. Recently, a comparison of different planar UWB monopole antennas was presented in [17], where still only circular, annual ring, and modified rectangular monopole antennas with different ground planes were studied.

In this paper, a group of nine planar UWB monopole antennas, using radiators of different shapes such as triangle, rectangle, square, annual ring, circle, horizontal ellipse, vertical ellipse, pentagon, and hexagon for body-centric wireless 


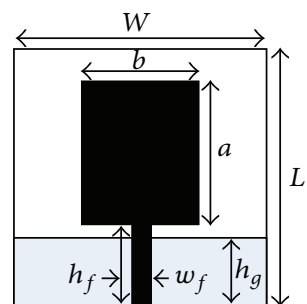

(a)

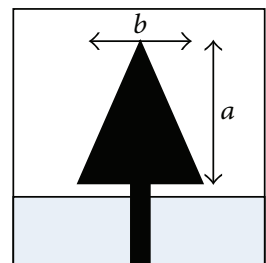

(b)

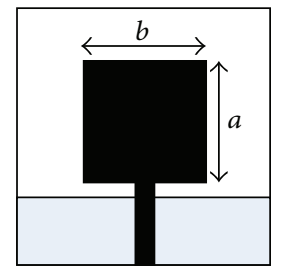

(c)

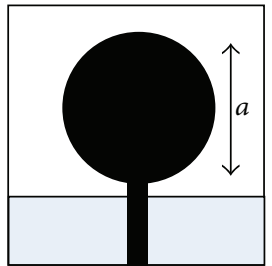

(d)

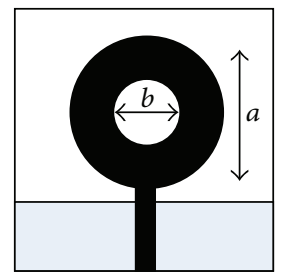

(e)

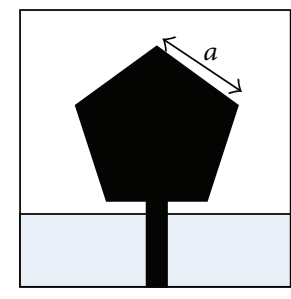

(h)

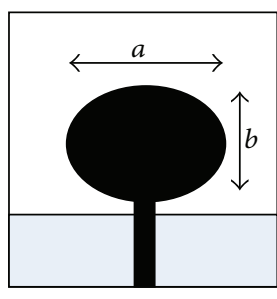

(g)

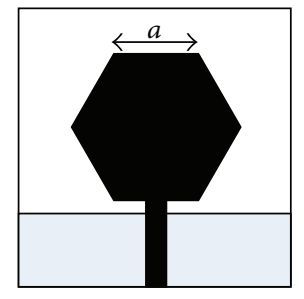

(i)

FIGURE 1: Geometries of monopoles using different radiator shapes: (a) rectangle, (b) triangle, (c) square, (d) circle, (e) annual ring, (f) vertical ellipse, (g) horizontal ellipse, (h) pentagon, and (i) hexagon.

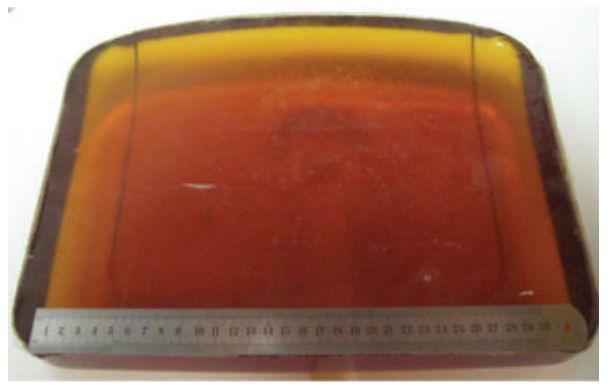

(a) Top view

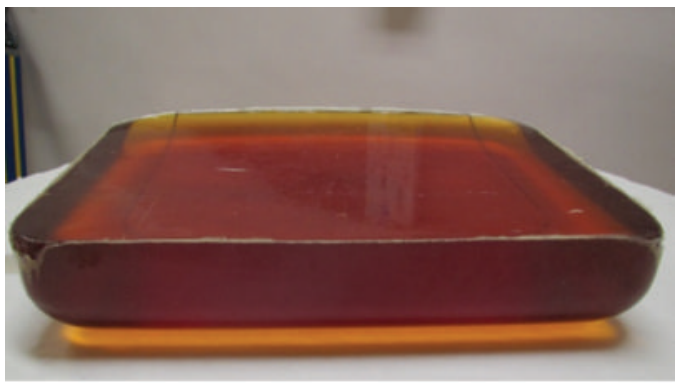

(b) Side view

FIGURE 2: Solid-body phantom for on-body measurement.

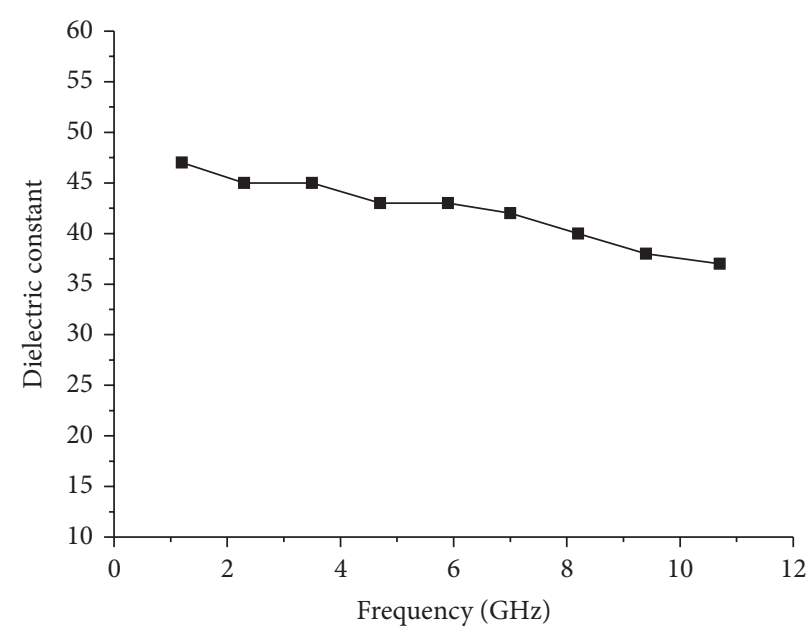

FIGURE 3: Dielectric constant characteristics of phantom. 


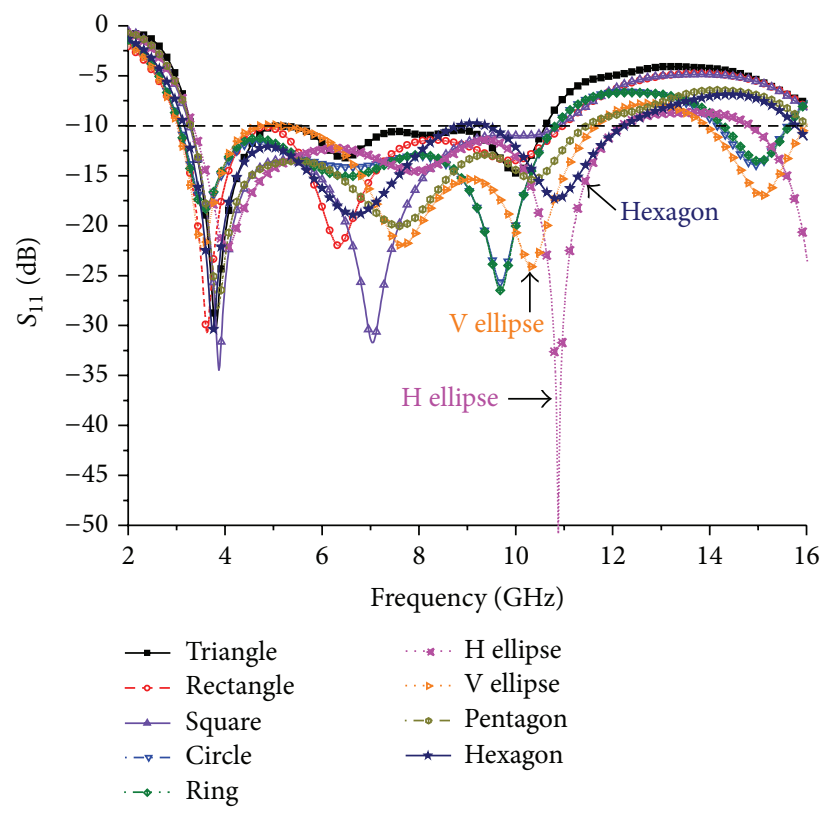

FIGURE 4: Reflection coefficients of different monopoles.

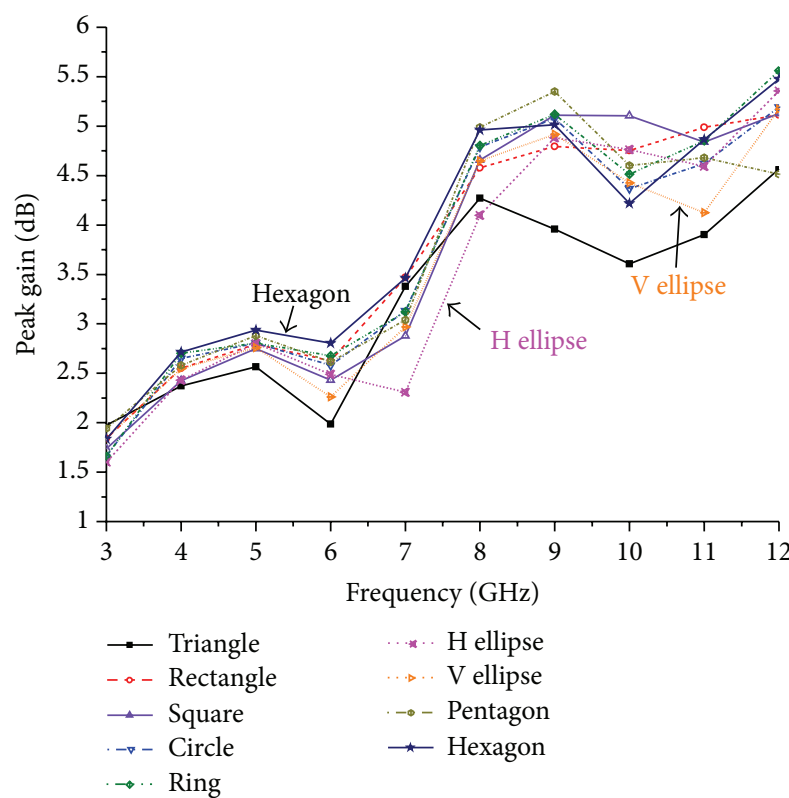

(a)

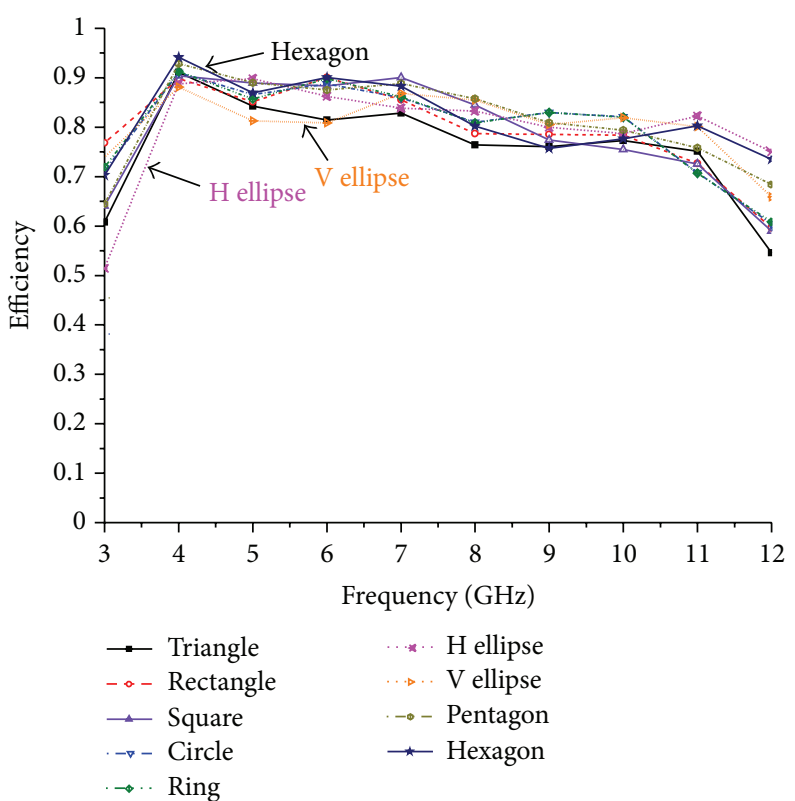

(b)

FIGURE 5: Simulated (a) peak gains and (b) efficiencies of different monopoles in free space.

communications, is studied using simulation and measurement. Similar works were briefly done in $[18,19]$ which used FR4 substrates and low-frequency liquid-body phantom. Due to the use of FR4 substrate, which had high loss at high frequencies and unstable electrical properties across the UWB, and also the use of low-frequency liquid-body phantom, there were large discrepancies between simulation and measurement results $[18,19]$, leading to uncertainties and doubts on the results. In this paper, the monopoles are all designed and fabricated on high-quality Rogers substrates and optimized using the EM simulation tool CST. A solidbody phantom having the same electrical characteristics as those of the human body across the UWB is made and used for studying the on-body performances of the monopoles. Results of computer simulation and measurement agree well. Studies show that, among all monopoles, the horizontal elliptical monopole has the better performances, in terms of impedance bandwidth, peak gain, efficiency, radiation pattern, path loss, and fidelity, for UWB body-centric wireless communications. 


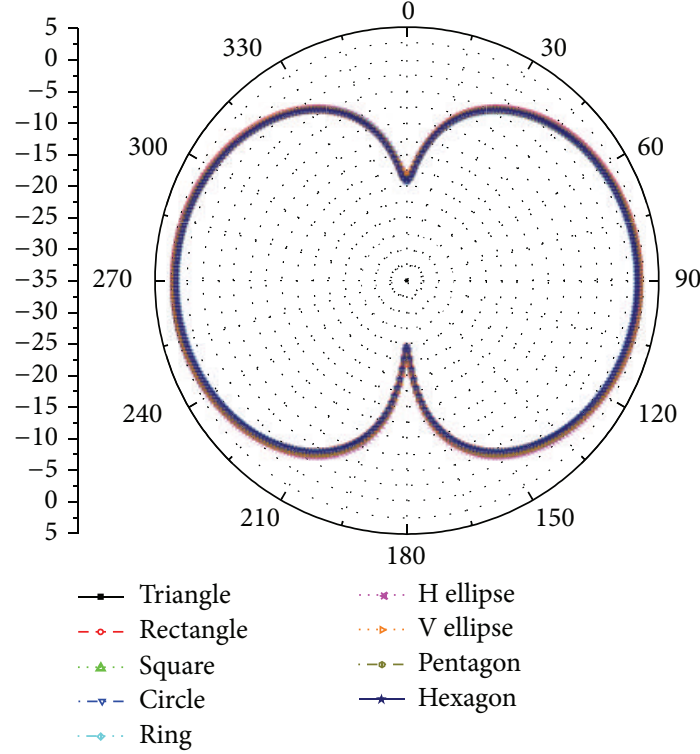

(a)

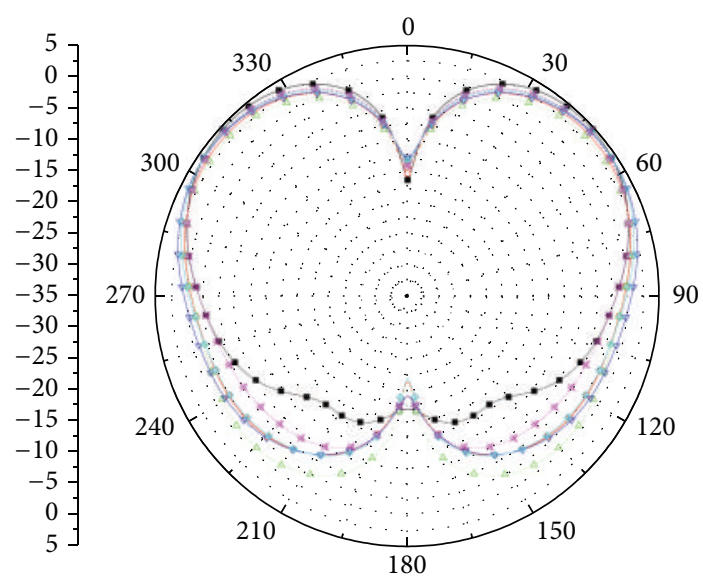

(c)

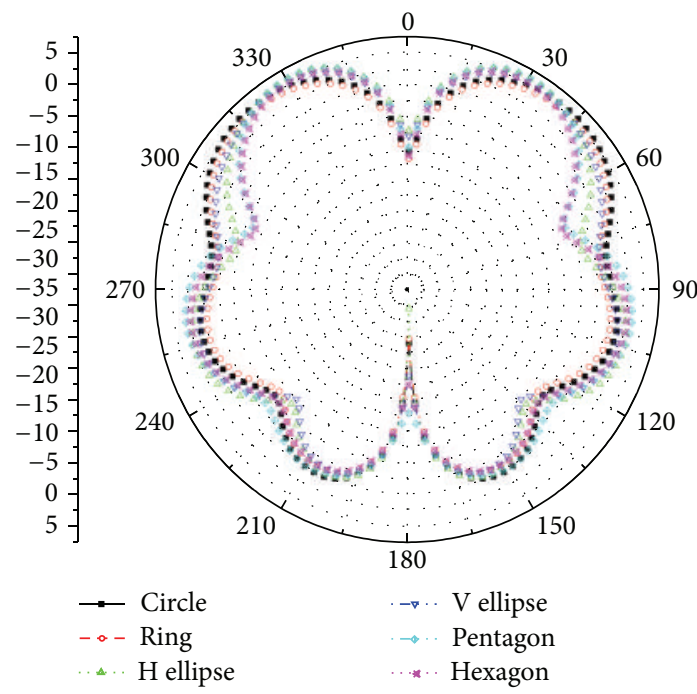

(e)

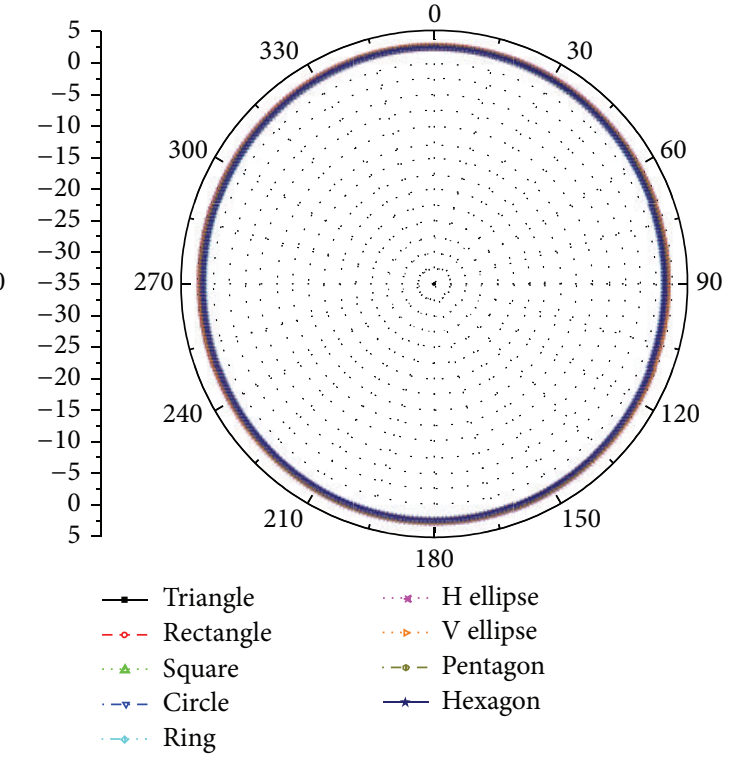

(b)

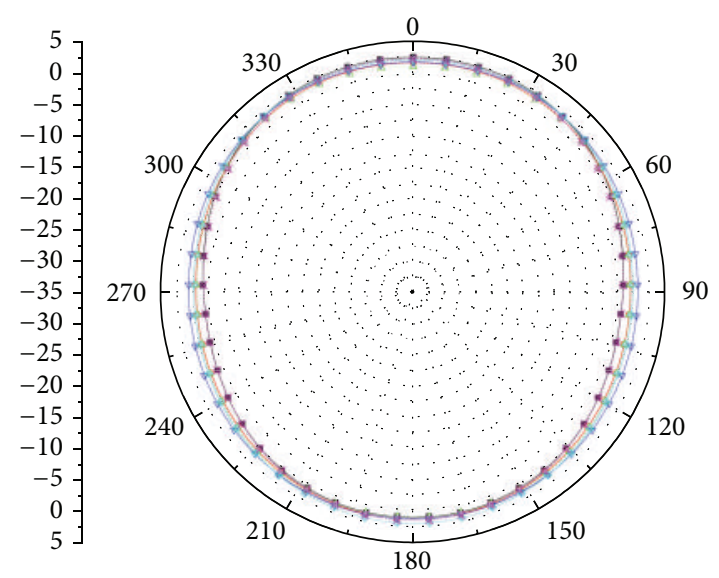

(d)

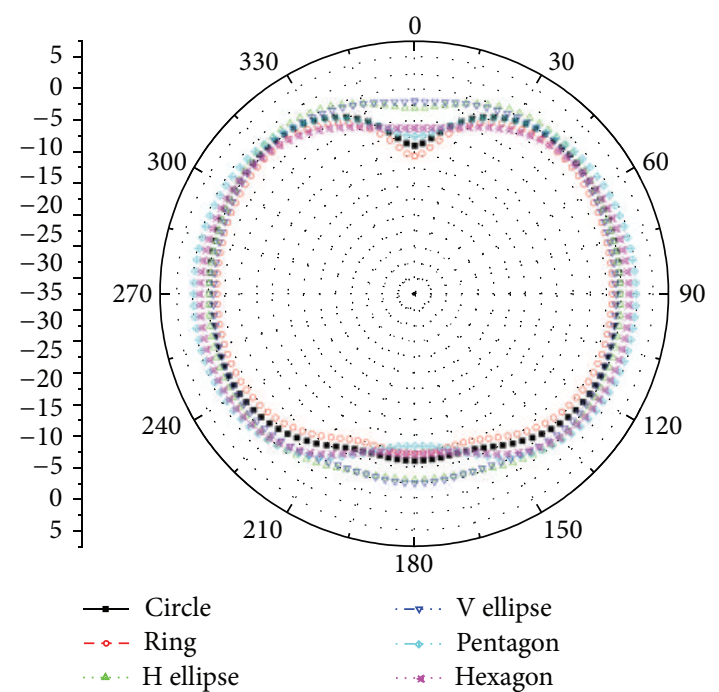

(f)

FIGURE 6: Simulated radiation patterns of different monopoles in free space at (a) $4 \mathrm{GHz}$, (c) $7 \mathrm{GHz}$, and (e) $11 \mathrm{GHz}$ in $x y$-plane and at (b) $4 \mathrm{GHz},(\mathrm{d}) 7 \mathrm{GHz}$, and (f) $11 \mathrm{GHz}$ in $x z$-plane. 


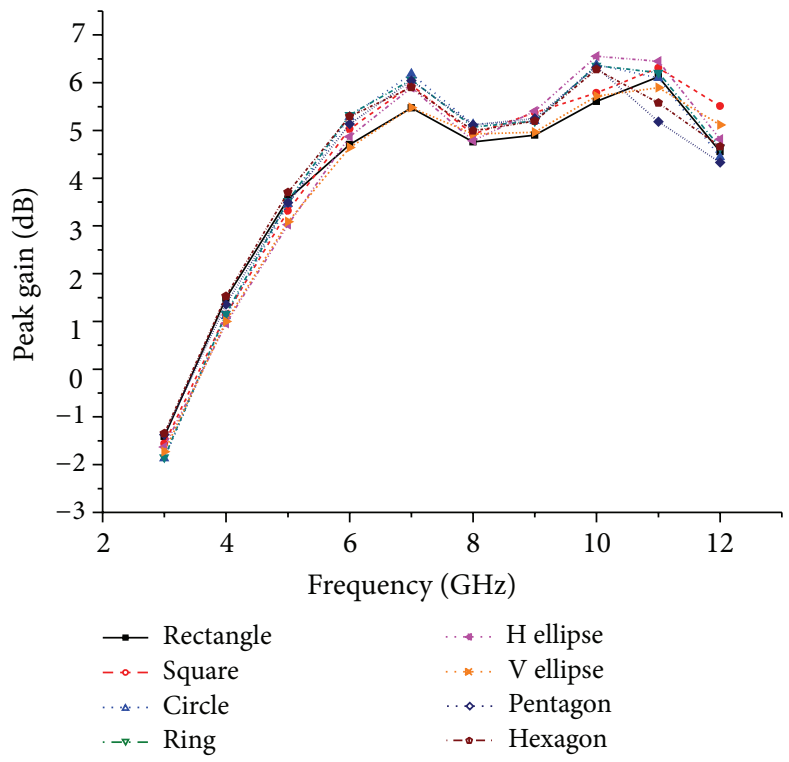

(a)

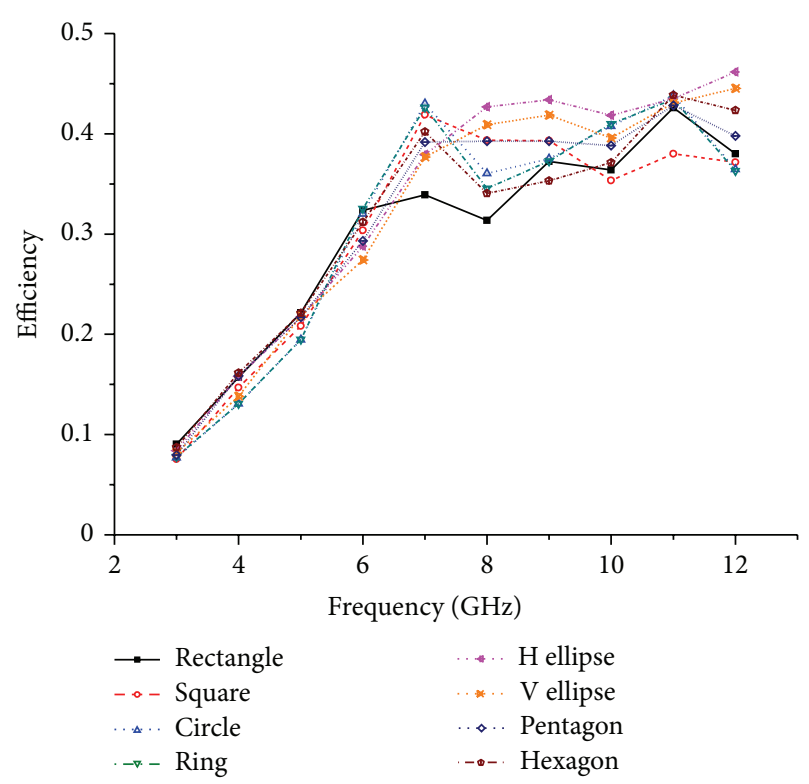

(b)

FIGURE 7: Simulated on-body (a) peak gains and (b) efficiencies of different monopoles.

\section{Monopoles Used for Studies}

The proposed planar UWB monopoles using radiators of different shapes, including triangle, rectangle, square, circle, annual ring, vertical ellipse, horizontal ellipse, pentagon, and hexagon, for computer simulation studies are shown in Figure 1. Each monopole is composed of a radiator fed by a microstrip line printed on one side of the substrate and a rectangular ground plane on the other side. The microstripfed line has a width of $w_{f}$ to achieve $50 \Omega$ characteristics impedance. The monopoles are designed on Rogers substrates with a thickness of $0.8 \mathrm{~mm}$, a relative permittivity of 3.5 , and a total size of $W \times L$ and optimized in terms of impedance bandwidth $\left(S_{11}<-10 \mathrm{~dB}\right)$ using computer simulation. All the monopoles in Figure 1 have the optimized parameters of $W=30 \mathrm{~mm}, L=35 \mathrm{~mm}, w_{f}=1.8 \mathrm{~mm}$, and $h_{g}=12 \mathrm{~mm}$, with other optimized parameters listed in Table 1 .

\section{Body Model and Phantom}

Human body has significant effects on the antenna characteristics. To design antennas for body-centric wireless communications, it is important to use a human body model in design. Two types of human body models are often used in simulation. One type is a three-tissue model which consists of skin, fat, and muscle tissues, while the other type is a homogeneous model which is composed of only muscle tissue [7]. Simulation results in [7] showed that there were only slight differences in results between using these two models [7]. Due to the simpler structure and shorter simulation time, we choose the homogeneous model in our studies. We select the dimension of the simulation body model to be $100 \times 100 \times$ $30 \mathrm{~mm}^{3}$ (simulation showed that a dimension larger than this did not make much difference on the results), a relative permittivity of 53.58, and a loss tangent of 0.2 .

In [20], a solid biological tissue-equivalent phantom was made using different chemicals, including polyethylene powder and sodium chloride, for UWB on-body measurements. The relative permittivity and conductivity of the phantom could be adjusted by using different composition ratios of polyethylene powder and sodium chloride when making it. For our studies, we made a solid biological tissueequivalent phantom having a dimension of $360 \times 260 \times$ $55 \mathrm{~mm}^{3}$, as shown in Figure 2 using the recipe in [20]. The average dielectric constants of human muscle and brain are about 50 and 40 [20]. Different methods have been proposed to measure the dielectric constant of materials [21-23]. In our studies, we place a resonant ring on the phantom and obtain a series of resonant frequencies across the UWB band. We use computer simulation to develop the same model, that is placing the resonant ring on a phantom, and vary the dielectric constant of the phantom to check the resonant frequencies. The dielectric constants producing the similar resonant frequencies to the measured ones are treated as the dielectric constants of the phantom.

The measured dielectric constant of our phantom is between 50 and 40 across the UWB from 3 to $10 \mathrm{GHz}$ as can be seen in Figure 3, so the phantom is suitable for on-body studies.

\section{Simulation and Measurement Results}

4.1. Simulation Results. The reflection coefficients $S_{11}$, peak gains, and efficiencies of the monopoles shown in Figure 1 are studied using computer simulation with results shown in Figures 4 and 5. It can be seen in Figure 4 that the horizontal 


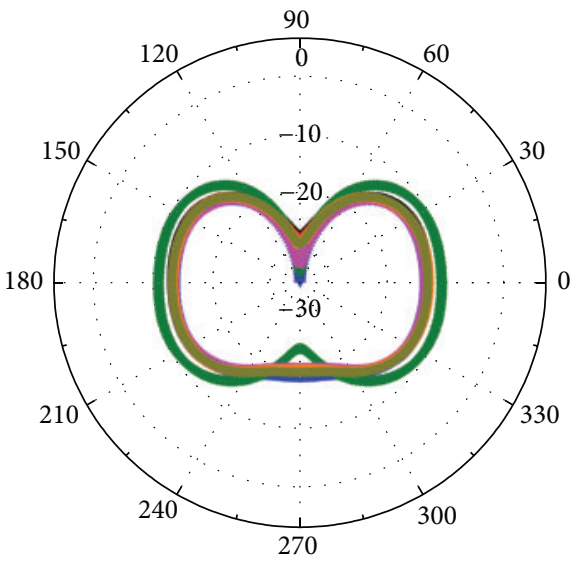

(a)

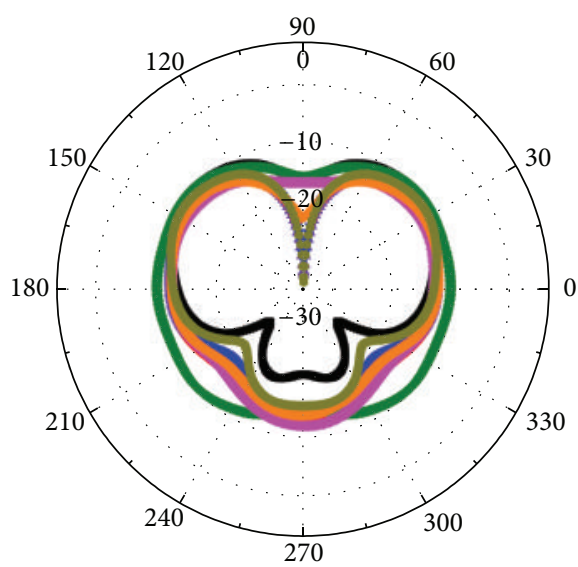

(c)
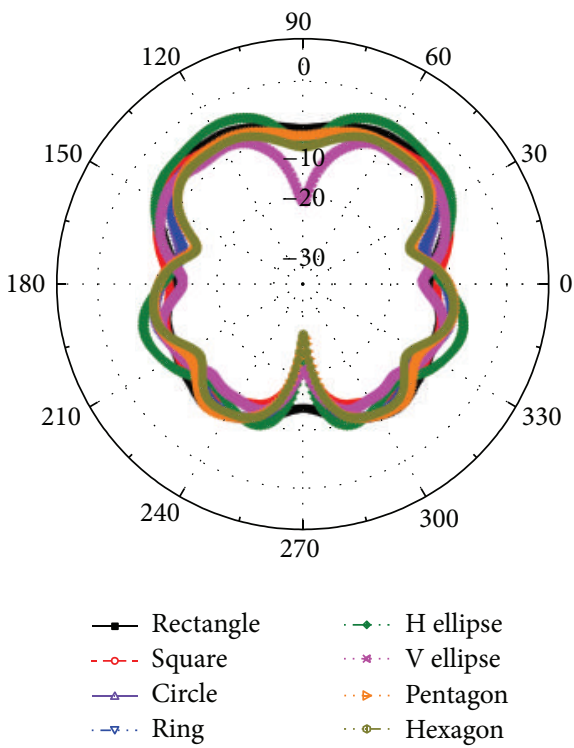

(e)

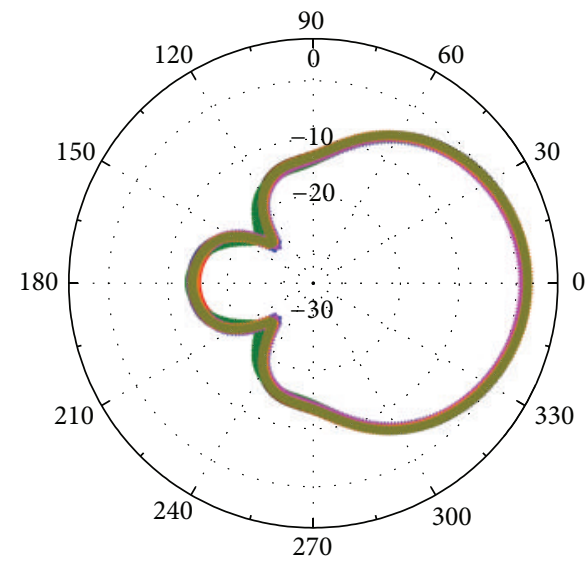

(b)

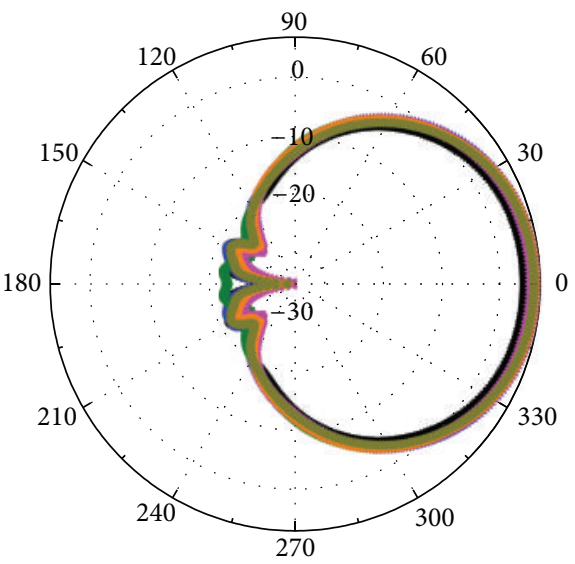

(d)
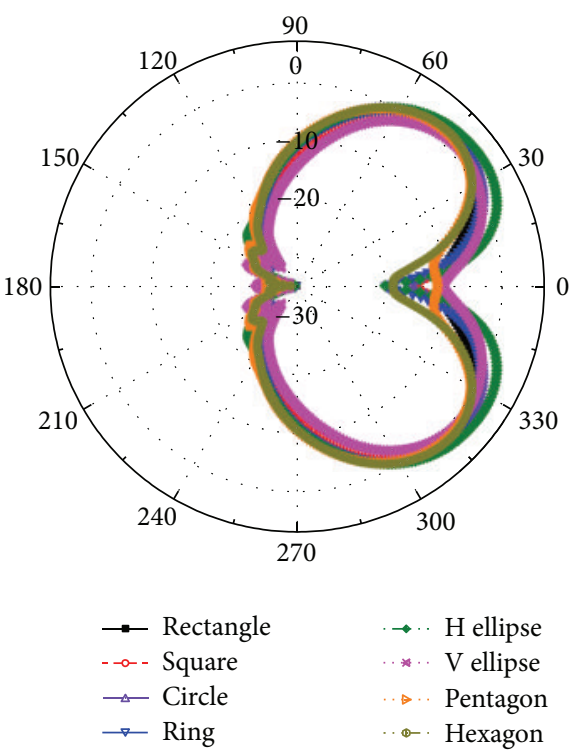

(f)

FIGURE 8: Simulated on-body radiation patterns of different monopoles at (a) $4 \mathrm{GHz}$, (c) $7 \mathrm{GHz}$, and (e) $11 \mathrm{GHz}$ in $x y$-plane and at (b) $4 \mathrm{GHz}$, (d) $7 \mathrm{GHz}$, and (f) $11 \mathrm{GHz}$ in $x z$-plane. 
TABLE 1: Dimensions of monopoles radiators (unit: $\mathrm{mm}$ ).

\begin{tabular}{lccccccccc}
\hline & Rectangle & Triangle & Square & Circle & Annual ring & V ellipse & H ellipse & Pentagon & Hexagon \\
\hline$h_{f}$ & 13.65 & 14 & 13.7 & 13 & 13 & 13.1 & 13 & 13.1 & 13.2 \\
$a$ & 16 & 16 & 13 & 16 & 16 & 16 & 16 & 10.4 & 9.24 \\
$b$ & 12.88 & 12 & 13 & & 6 & 12 & 12 & & \\
\hline
\end{tabular}

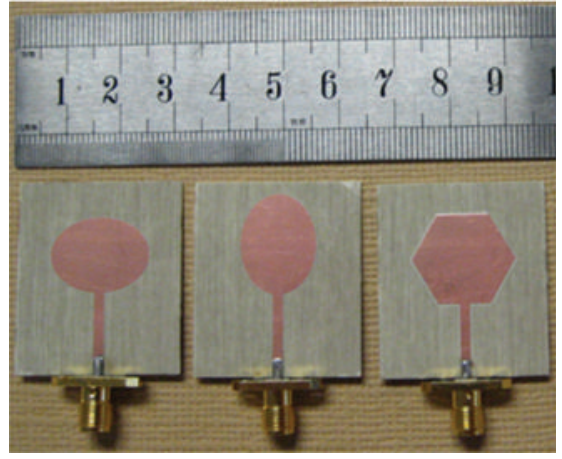

(a) Top view

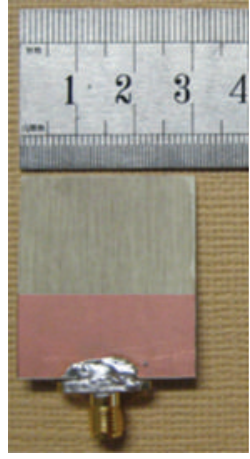

(b) Bottom view
FIGURE 9: Prototypes of horizontal elliptical, vertical elliptical, and hexagonal monopoles.

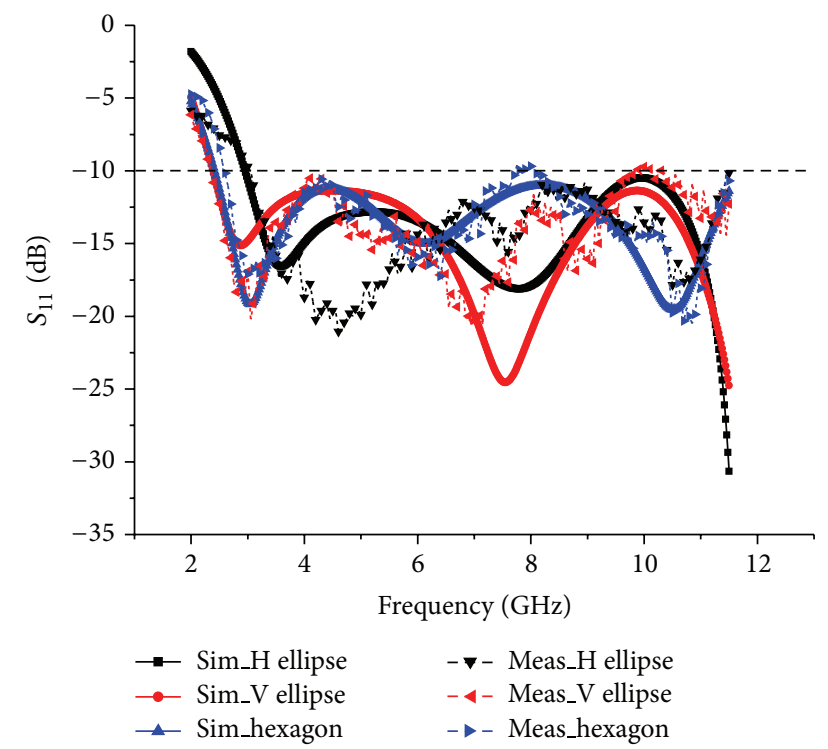

FIgURE 10: Simulated and measured $S_{11}$ of horizontal elliptical, vertical elliptical, and hexagonal monopoles.

elliptical antenna has the widest impedance bandwidth (for $\mathrm{S}_{11}<-10 \mathrm{~dB}$ ) of $3.1-12 \mathrm{GHz}$ (wider than the UWB). While the triangular monopole has the narrowest bandwidth of 3.3$10.6 \mathrm{GHz}$ which is less than the UWB, so it is taken out for further studies. The simulated peak gains and efficiencies of the monopoles are shown in Figure 5. It can be seen that the performances of the monopoles vary with frequency, so it is difficult to assess them based on the results. Moreover, the gain plots in Figure 5(a) can be misleading because the radiation patterns are directional particularly at high frequencies (which are shown later). As a result, we use the averaged gains and efficiencies over the UWB. Results showed that the hexagonal monopole has the highest average peak gain and efficiency of about $3.65 \mathrm{dBi}$ and $80 \%$, respectively. This is followed by the horizontal elliptical monopole and vertical elliptical monopoles which have the average peak gains of about $3.44 \mathrm{dBi}$ and $3.32 \mathrm{dBi}$, respectively, with the corresponding average efficiencies of $80 \%$ and $78 \%$. These monopoles are the best among the monopoles studied.

The simulated radiation patterns of the monopoles at the frequencies of 4, 7, and $11 \mathrm{GHz}$ are shown in Figure 6. The radiation patterns are all almost omnidirectional in the $x z$ plane (i.e., $H$-plane) at 4 and $7 \mathrm{GHz}$, typical for monopole antennas. However, at $11 \mathrm{GHz}$, only the vertical and horizontal elliptical monopoles have omnidirectional radiation patterns. The radiation patterns of all monopoles have obvious nulls in the $x z$-plane (i.e., E-plane), also typical for monopole antennas. For body-centric communications, the radiation in the $E$-plane plays a more important role. The vertical and horizontal elliptical monopoles have less fluctuation in the radiation patterns and so are better.

The gains and efficiencies of these monopoles on human body are studied using computer simulation. In these studies, a human model is developed using the CST and each of the monopoles is placed flat on the phantom for simulation. In practice, there will be an air gap between the on-body antenna and the human skin. In our simulation tests, we choose this gap to be $3 \mathrm{~mm}$ which was also used by others [7]. The simulated on-body peak gains and efficiencies of the monopoles are shown in Figure 7. It can be seen in Figure $7(\mathrm{a})$ that the differences in gain of the monopoles are less than $1 \mathrm{~dB}$. Again, since the performances of the monopoles vary with frequency, the average values across the UWB are computed and used to assess their performances. Results show that the hexagonal, horizontal elliptical, and vertical elliptical monopoles have the average peak gains 4.18, 4.36 , and $4.07 \mathrm{dBi}$, respectively, which are higher than those in free space. This is because the human body has made the monopoles more directional, as evident in Figure 8 which shows the radiation patterns of the on-body monopoles at 4,7 , and $11 \mathrm{GHz}$. Front-to-back ratio is important for safety reason. In body-centric communications system, the antenna used should have as large front-to-back ratio as possible in the plane perpendicular to the body surface. It does not need any specific directionality but requires good signal transmission and reception in the directions along the body surface. Most antennas proposed such as in $[7,8,24]$ for body-centric 


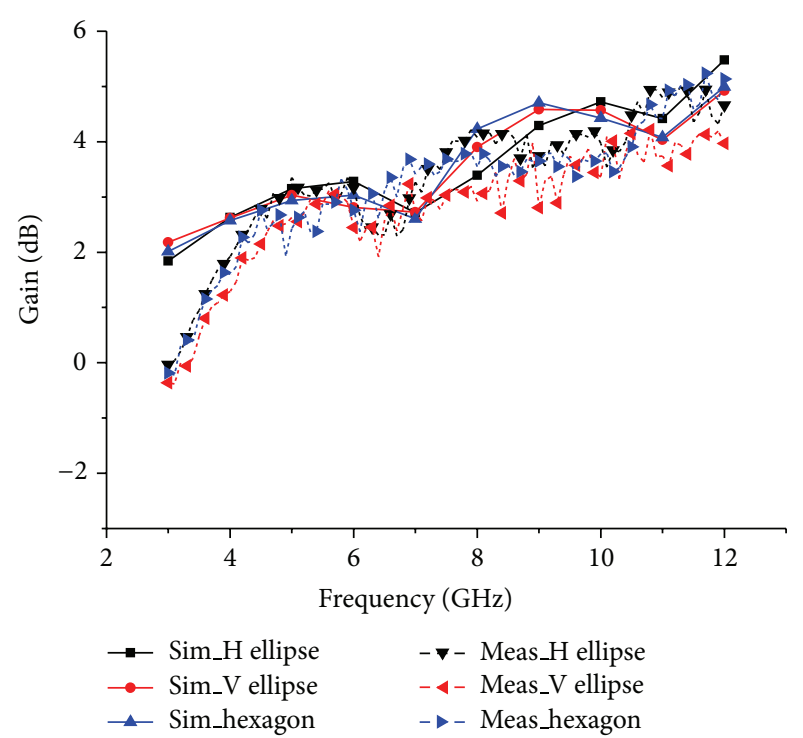

(a)

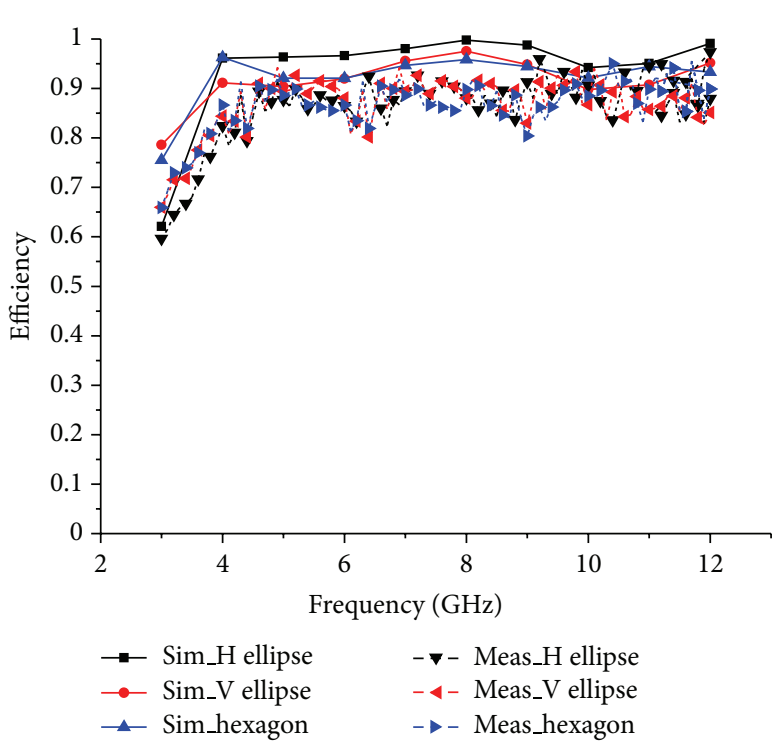

(b)

FIGURE 11: Simulated and measured (a) peak gains and (b) efficiencies of different monopoles in free space.

wireless communications had a front-to-back ratio from 10 to $30 \mathrm{~dB}$. Figures 8(d), 8(e), and 8(f) show that the front-to-back ratios of the antennas are in the range of about $20-30 \mathrm{~dB}$. Thus compared with the antennas in $[7,8,24]$, these antennas have less power radiated towards human body and more power used for communications. For efficiency, the hexagonal, horizontal elliptical, and vertical elliptical monopoles have the averages of $30 \%, 31 \%$, and $30 \%$, respectively, which are lower than those in free space. Compared with the corresponding efficiencies in free space, the human body significantly has reduced the efficiency.

4.2. Measurement Results. Simulation results in previous section show that the hexagonal, horizontal, and vertical elliptical monopoles have the better overall performances in terms of bandwidth, average gain, average efficiency, and radiation pattern. These monopoles are prototyped as shown in Figure 9 for measurement in free space and on the phantom of Figure 2.

The simulated and measured $S_{11}$ of the three monopoles in free space are shown in Figure 10. It can be seen that simulated and measured results agreed well. The three monopoles have the impedance bandwidths $\left(\mathrm{S}_{11}<-10 \mathrm{~dB}\right)$ larger than the UWB of 3.1 to $10.6 \mathrm{GHz}$, with the two elliptical antennas having lower cutoff frequencies. The simulated and measured peak gains and efficiencies of the monopoles in free space are shown in Figure 11. The average peak gain and efficiency of the horizontal elliptical monopole are computed to be about $3.20 \mathrm{dBi}$ and $87 \%$, respectively. The vertical elliptical and hexagonal monopoles have the average peak gains of 2.74 and $2.99 \mathrm{dBi}$, respectively, with the corresponding average efficiencies of $85 \%$ and $87 \%$. The simulated and measured radiation patterns of the monopoles at 4,7 , and $11 \mathrm{GHz}$ in free space are shown in Figure 12, which also indicates good agreements.

In on-body measurement, each of the prototyped monopoles is placed at the centre of the phantom shown in Figure 2 with a gap of $3 \mathrm{~mm}$ from the surface. The whole setup is placed in the antenna measurement equipment, the Satimo Starlab system. The simulated and measured peak gains and efficiencies of the monopoles on body are shown in Figure 13. The horizontal elliptical monopole has the highest average peak gain and efficiency of $4.35 \mathrm{dBi}$ and $32 \%$, respectively, across the UWB, while the vertical elliptical and hexagon monopoles have the average peak gains of $3.86 \mathrm{dBi}$ and $3.82 \mathrm{dBi}$ and the average efficiency of $26.5 \%$ and $30.2 \%$, respectively. Figure 14 shows the radiation patterns of the monopoles at 4,7 , and $11 \mathrm{GHz}$. It can be seen that the on-body radiation patterns in the $x y$-plane ( $E$-plane) are quite poor compared with those in free space. This is because the human body absorbs a significant amount of radiated power, leading to the low efficiencies measured on body. Adding a reflector between the antenna and the human body could reduce the effect of the human body and improve the radiation pattern of the antenna, but this would make the antenna high profile and not convenient for body-centric wireless communications. The radiation patterns in the $E$-plane have only one single null, which will be better for on-body communications. Since the radiation pattern in the $E$-plane plays an important role in body-centric communications, the results in Figures 14(a), 14(b), and 14(c) show that the horizontal elliptical monopole has slightly larger radiation patterns in the $E$-plane and so is better. In the $x z$-plane ( $H$-plane), the radiation patterns are directional, with front-to-back ratios of about $20-30 \mathrm{~dB}$, which will be suitable for off-body communications. The horizontal elliptical monopole has slightly larger radiation patterns and so again is better. 


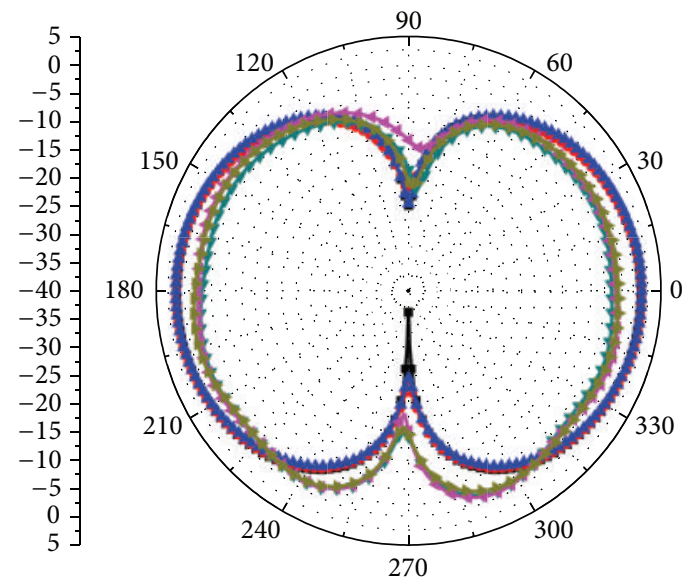

(a)

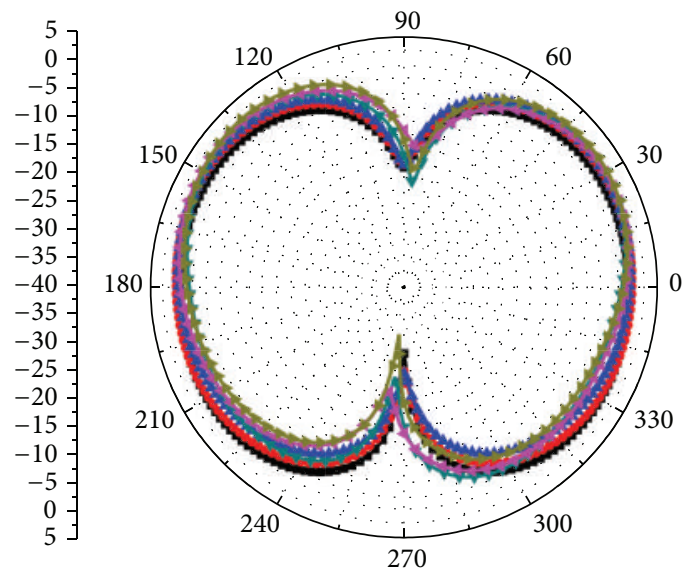

(c)
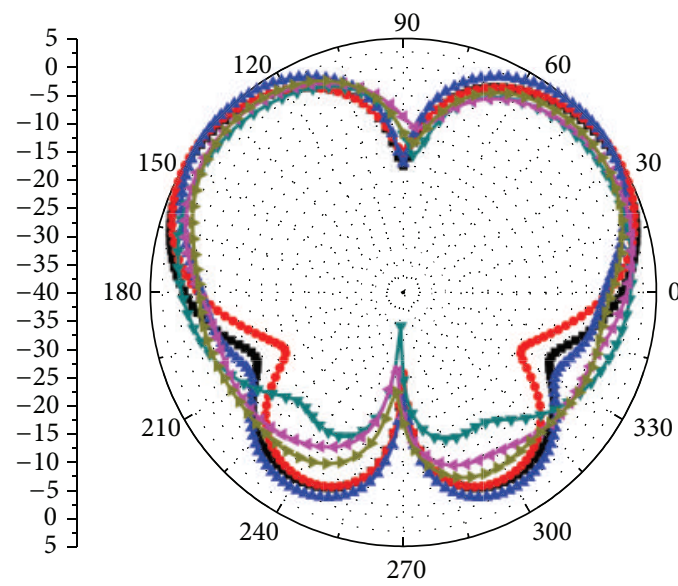

$\rightarrow$ Sim_H ellipse $\rightarrow$ Meas_H ellipse
$\rightarrow$ Sim_V ellipse $\rightarrow$ Meas_V ellipse
$\rightarrow$ Sim_hexagon $\rightarrow$ Meas_hexagon

(e)

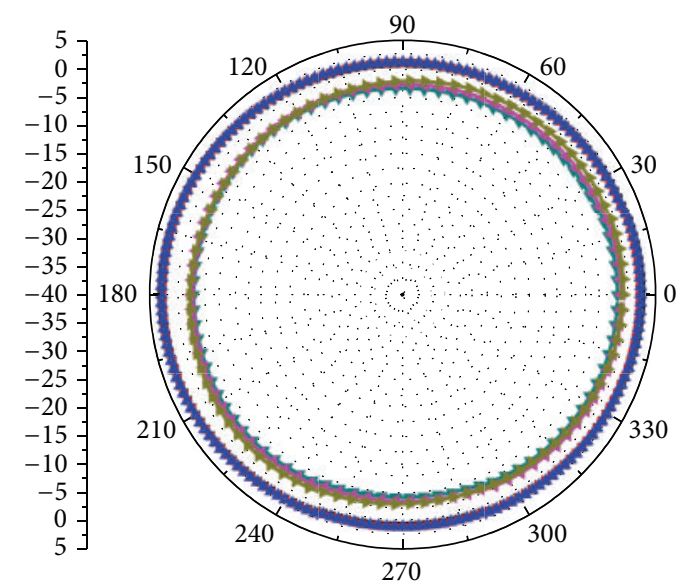

(b)

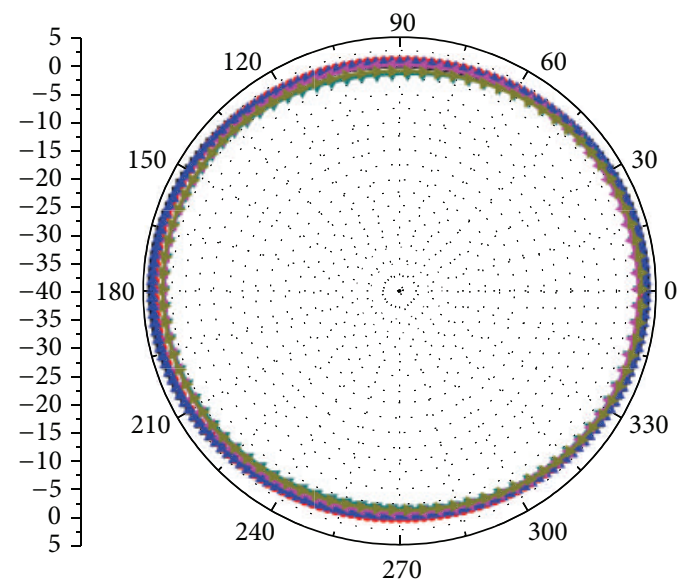

(d)

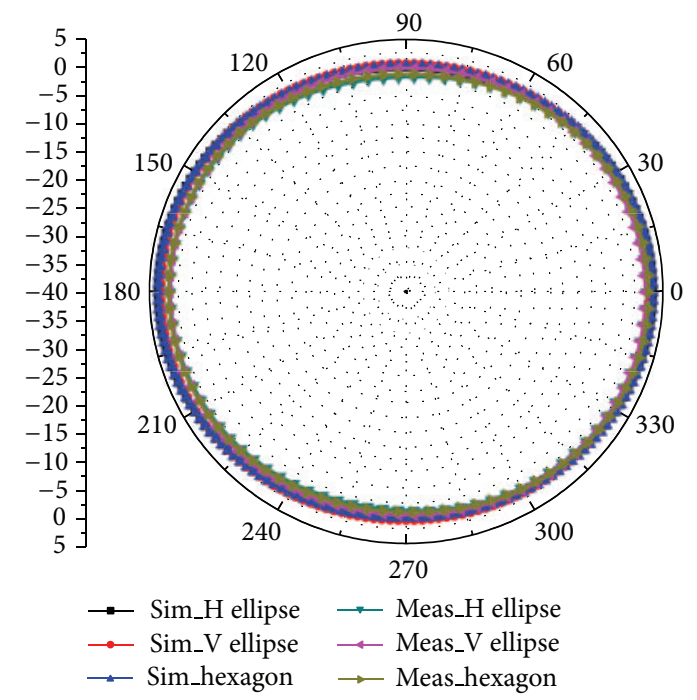

(f)

FIGURE 12: Simulated and measured radiation patterns of different monopoles at (a) $4 \mathrm{GHz}$, (c) $7 \mathrm{GHz}$, (e) $11 \mathrm{GHz}$ in $x y$-plane, (b) $4 \mathrm{GHz}$, (d) $7 \mathrm{GHz}$, and (f) $11 \mathrm{GHz}$ in $x z$-plane in free space. 


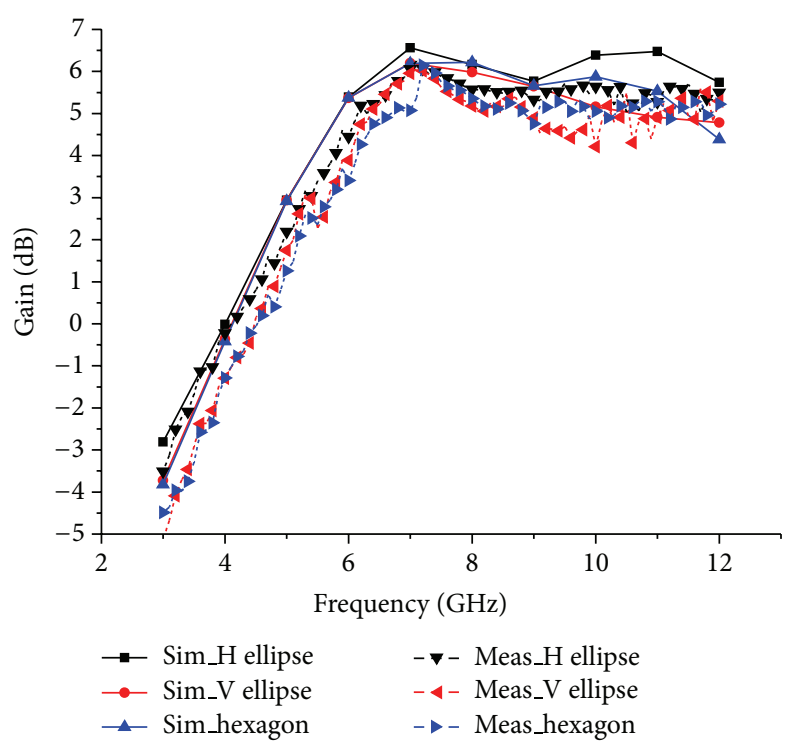

(a)

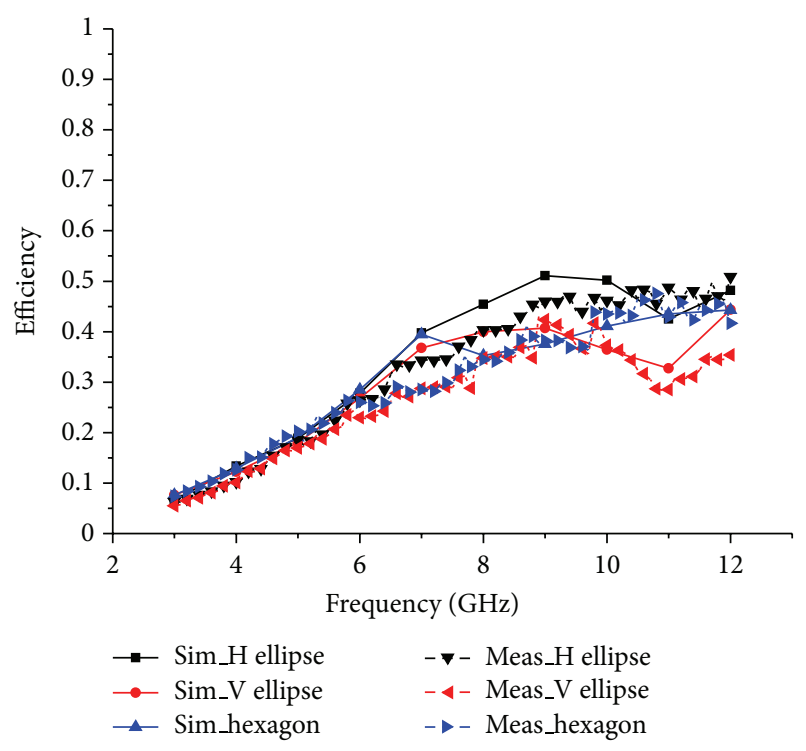

(b)

FIGURE 13: Simulated and measured on-body (a) peak gains and (b) efficiencies of different monopoles.

It is well known that the path loss of signal at a transmitter-receiver distance $d$ can be written as

$$
P_{d B}(d)=P_{d B}\left(d_{0}\right)+n \cdot 10 \log \left(\frac{d}{d_{0}}\right)
$$

where $d_{0}$ is a reference distance, $P_{d B}\left(d_{0}\right)$ is the path loss value at the reference distance, and $n$ is the path loss constant. Path loss is a major factor in the design of wireless communication systems. Compared with other wireless communication, body-centric wireless communication has some distinct requirements, for example; it requires to use low transmit power, thus the path loss should be as low as possible. The on-body path losses of signals emitted by the three monopoles are also measured using the phantom of Figure 2. In the measurements, two identical monopoles with the same orientation are placed side-by-side and $1 \mathrm{~cm}$ from the phantom surface, as shown in Figure 15. Figure 16 shows the measured results and the best fitted line using the least square fitting method. The exponent loss constants $n$ derived from the best fitted line in Figure 16 are 4.5, 4.6, and 4.8 for the horizontal elliptical and vertical elliptical and hexagonal monopoles, respectively. The horizontal elliptical monopole has the least path loss constant of $1.8 \mathrm{~dB} / \mathrm{cm}$. For comparison, the path losses in free space of the three antennas are also shown in Figure 16. The exponent loss constants $n$ are 2.43, 2.47 , and 2.85 for the horizontal elliptical and vertical elliptical and hexagonal monopoles in free space, respectively, with the horizontal elliptical monopole having the least path loss constant of $0.72 \mathrm{~dB} / \mathrm{cm}$. Compared with the path losses in free space, the existence of the phantom has significant effects on the path losses of the antennas.
The fidelity of an antenna can be calculated to assess the quality of the received pulse. The fidelity $F$ is defined [25] as

$$
F=\max \frac{\int_{-\infty}^{+\infty} f(t) \cdot r(t+\tau) d t}{\sqrt{\int_{-\infty}^{+\infty}\left|f(t)^{2}\right| d t \cdot \int_{-\infty}^{+\infty}\left|r(t+\tau)^{2}\right| d t}},
$$

where $f(t)$ is the transmit signal and $r(t)$ is the received signal. A significant difference between conventional radio transmission systems and UWB systems is that UWB systems transmit information by generating radio energy in specific time intervals and so occupying a large bandwidth. Pulse modulation is more appropriate. In such modulation, the waveform of the pulse should be preserved at the receiver. Fidelity $F$ is a measure of the similarity between transmitted and received waveforms and so is important for UWB bodycentric wireless communications. The fidelities of these three antennas are measured as shown in Figure 15 with a distance of $1 \mathrm{~cm}$ above the phantom and a distance of $30 \mathrm{~cm}$ between the transmitted antenna and received antenna. Results show that the fidelity values of the horizontal elliptical, vertical elliptical, and hexagonal monopoles are $92.6 \%, 88.1 \%$, and $81.5 \%$, respectively, which means the horizontal elliptical monopole has the best fidelity among all.

\section{Conclusions}

The results of studies on the performances of a group of planar UWB monopoles with different shapes of radiators for body-centric wireless communications have been presented. A solid-body phantom having the same characteristic as those of the human body is made and used for the study of the monopoles for body-centric wireless communications. Results of the simulation and measurement have showed 


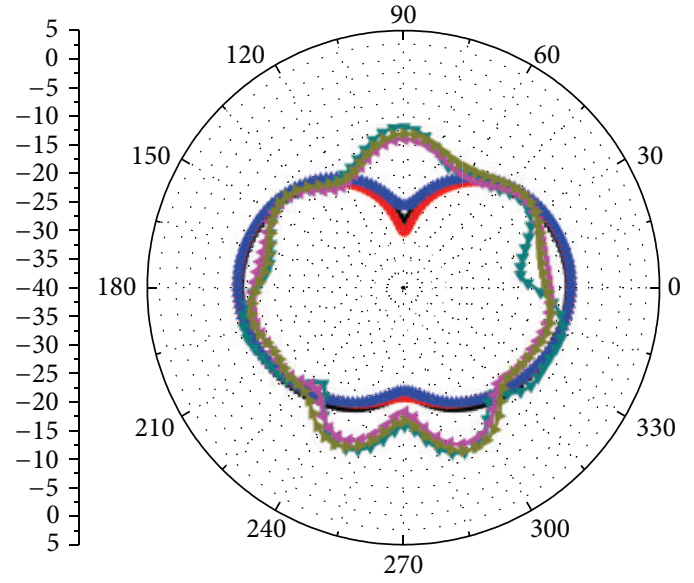

(a)
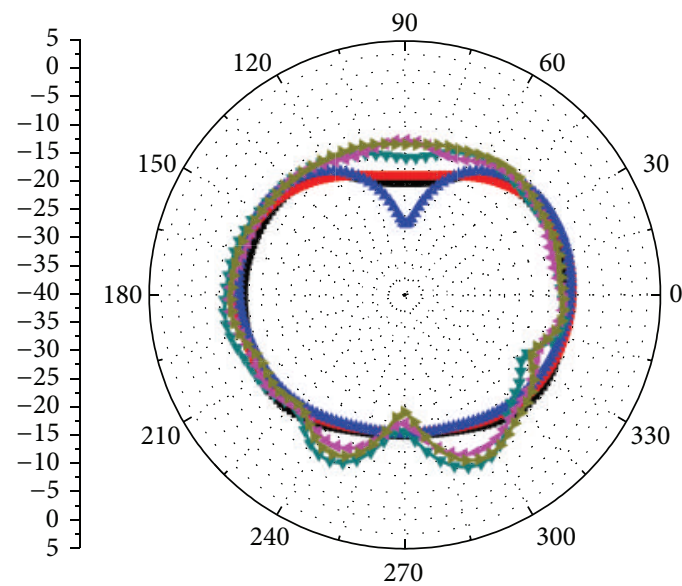

(c)

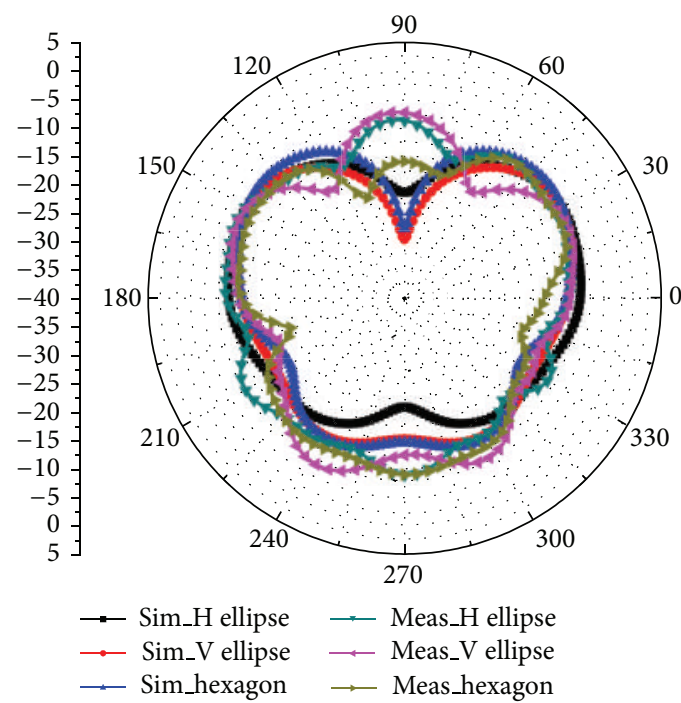

(e)

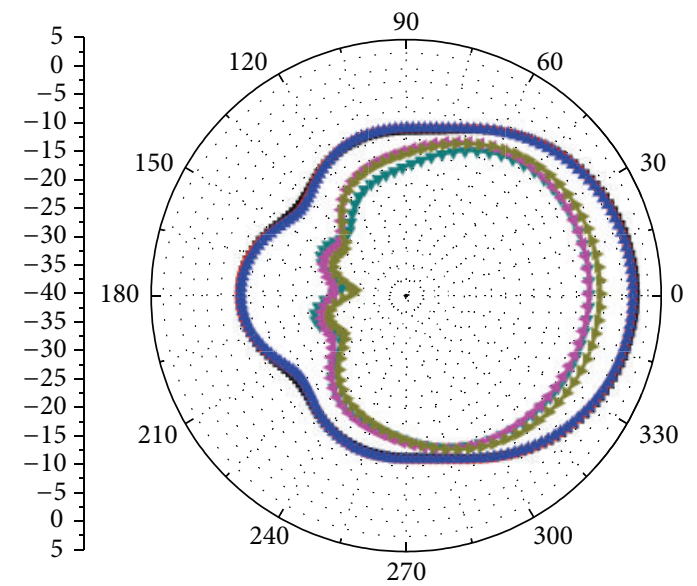

(b)

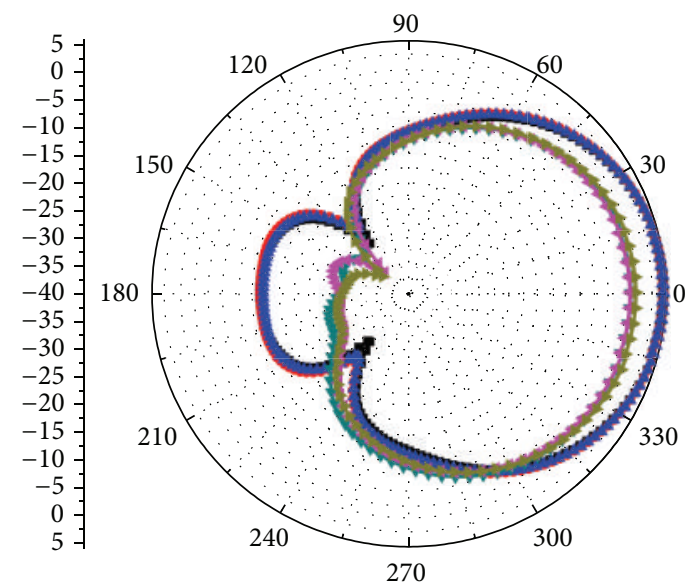

(d)
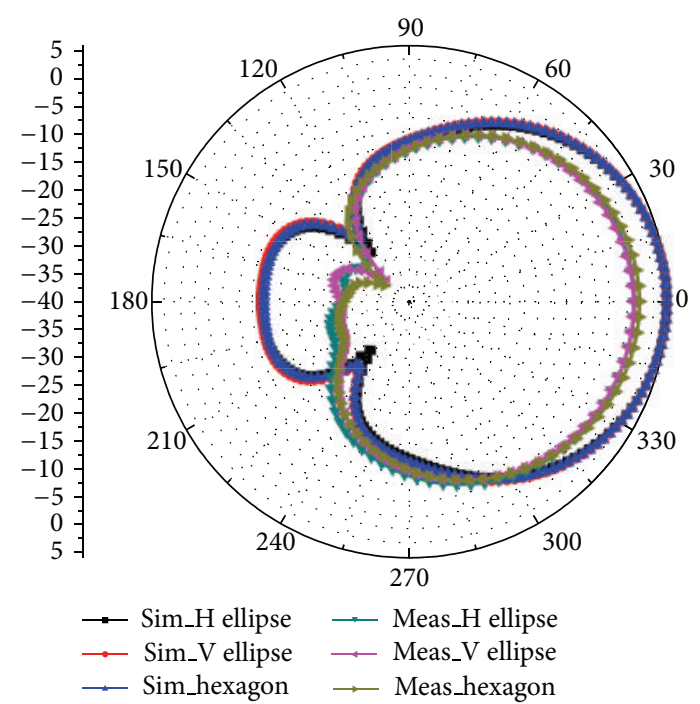

(f)

FIGURE 14: Simulated and measured on-body radiation patterns of different monopoles at (a) $4 \mathrm{GHz}$, (c) $7 \mathrm{GHz}$, and (e) $11 \mathrm{GHz}$ in $x y$-plane and at (b) $4 \mathrm{GHz}$, (d) $7 \mathrm{GHz}$, and (f) $11 \mathrm{GHz}$ in $x z$-plane. 


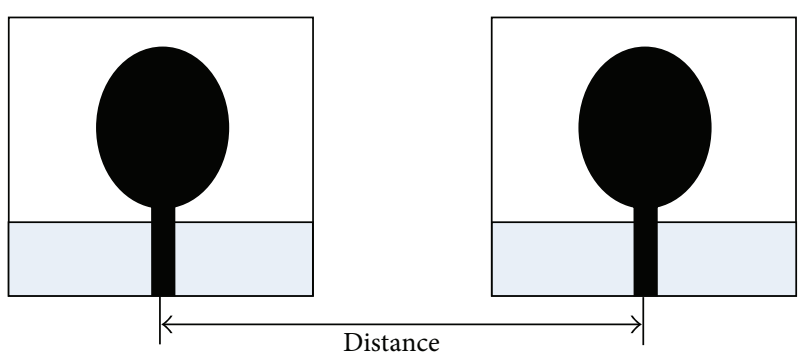

FIGURE 15: Layout for path loss measurement.

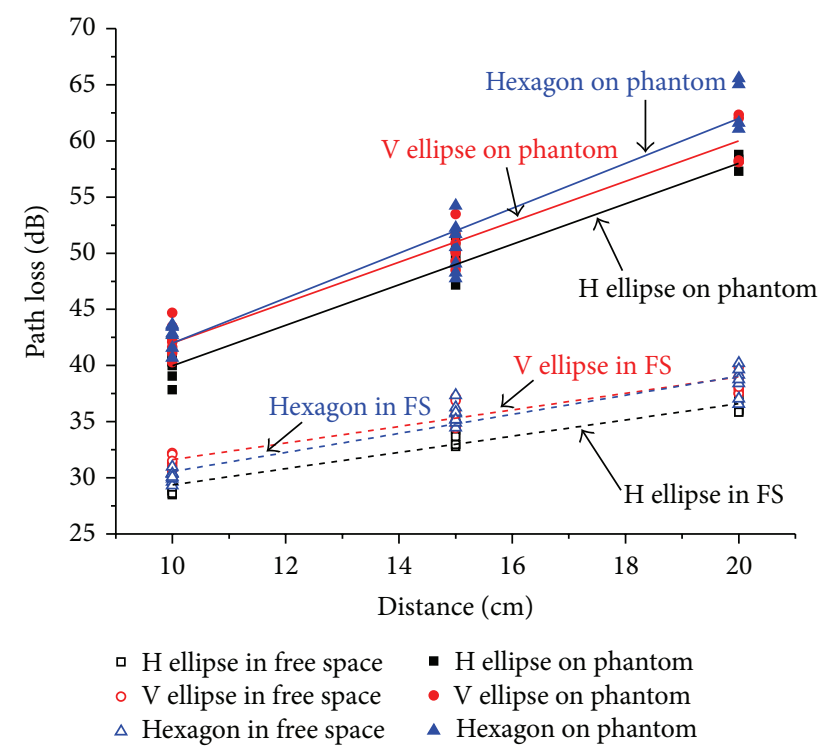

Figure 16: Measured path losses of monopoles in free space and on phantom.

that the horizontal elliptical monopole has the better overall performances in terms of bandwidth, gain, and radiation pattern, both in free space and on body. For on-body measured results, the horizontal elliptical monopole can achieve a bandwidth from 3.1 to $12 \mathrm{GHz}$, an average peak gain of about $4.35 \mathrm{dBi}$, an average efficiency of $32 \%$, a path loss of $1.8 \mathrm{~dB} / \mathrm{cm}$, a fidelity of $92.6 \%$, and good radiation patterns in the $E$-plane, making it a good candidate for UWB body-centric wireless communications.

\section{References}

[1] Federal Communications Commission, "Revision of part 15 of the commission's rules regarding ultra-wideband transmission system from 3.1 to $10.6 \mathrm{GHz}$," in Federal Communications Commission, pp. 98-153, ET-Docket, Washington, DC, USA, 2002.

[2] D. B. Lin, I. T. Tang, and M. Y. Tsou, "A compact UWB antenna with CPW-fed," Microwave and Optical Technology Letters, vol. 49, no. 2, pp. 372-375, 2007.

[3] Y.-J. Ren and K. Chang, "Ultra-wideband planar elliptical ring antenna," Electronics Letters, vol. 42, no. 8, pp. 447-449, 2006.
[4] J. Liang, C. C. Chiau, X. Chen, and C. G. Parini, "Printed circular ring monopole antennas," Microwave and Optical Technology Letters, vol. 45, no. 5, pp. 372-375, 2005.

[5] K. Kiminami, A. Hirata, and T. Shiozawa, "Double-sided printed bow-tie antenna for UWB communications," IEEE Antennas and Wireless Propagation Letters, vol. 3, no. 1, pp. 152-153, 2004.

[6] M. Al-Husseini, A. Ramadan, A. El-Hajj, and K. Y. Kabalan, "Design of a compact and low-cost fractal-based UWB PCB Antenna," in Proceedings of the 26th National Radio Science Conference (NRSC '09), pp. B24.1-B24.8, Cairo, Egypt, March 2009.

[7] P. S. Hall and Y. Hao, Antennas and Propagation for Body-Centric Wireless Communications, Artech House, Norwood, Mass, USA, 2006.

[8] A. Alomainy, A. Sani, A. Rahman, J. G. Santas, and Y. Hao, "Transient characteristics of wearable antennas and radio propagation channels for ultrawideband body-centric wireless communications," IEEE Transactions on Antennas and Propagation, vol. 57, no. 4, pp. 875-884, 2009.

[9] X. N. Low, Z. N. Chen, and T. S. P. See, "A UWB dipole antenna with enhanced impedance and gain performance," IEEE Transactions on Antennas and Propagation, vol. 57, no. 10, pp. 29592966, 2009.

[10] A. Alomainy, Y. Hao, C. G. Parini, and P. S. Hall, "Comparison between two different antennas for UWB on-body propagation measurements," IEEE Antennas and Wireless Propagation Letters, vol. 4, no. 1, pp. 31-34, 2005.

[11] A. Cai, T. S. P. See, and Z. N. Chen, "Study of human head effects on UWB antenna," in Proceedings of the IEEE International Workshop on Antenna Technology: Small Antennas and Novel Metamaterials (IWAT '05), pp. 310-313, March 2005.

[12] Z. N. Chen, A. Cai, T. S. P. See, X. Qing, and M. Y. W. Chia, "Small planar UWB antennas in proximity of the human head," IEEE Transactions on Microwave Theory and Techniques, vol. 54, no. 4, pp. 1846-1856, 2006.

[13] “Bodymedia Body Monitoring Technologies," http://www.bodymedia.com/.

[14] L. Vallozzi, P. Van Torre, C. Hertleer, H. Rogier, M. Moeneclaey, and J. Verhaevert, "Wireless communication for firefighters using dual-polarized textile antennas integrated in their garment," IEEE Transactions on Antennas and Propagation, vol. 58, no. 4, pp. 1357-1368, 2010.

[15] X. H. Wu and Z. N. Chen, "Comparison of planar dipoles in UWB applications," IEEE Transactions on Antennas and Propagation, vol. 53, no. 6, pp. 1973-1983, 2005.

[16] M. Klemm, I. Z. Kovacs, G. Troster et al., "Comparison of directional and omni-directional UWB antennas for wireless body area network applications," in Proceedings of the 18th International Conference on Applied Electromagnetics and Communications held Jointly with COST 284 Workshop, pp. 1-4, October 2005.

[17] R. Kalra and S. Kaur, "Comparison of different planar monopole UWB antenna using HFSS," International Journal of Sientific \& Engineering Research, vol. 2, no. 10, 2011.

[18] Y. Y. Sun, S. W. Cheung, and T. I. Yuk, "Studies of planar antennas with different radiator shapes for ultra-wideband body-centric wireless communications," in Proceedings of the Progress in Electromagnetics Research Symposium (PIERS '11), pp. 1415-1419, Suzhou, China, September 2011.

[19] Y. Y. Sun, S. W. Cheung, and T. I. Yuk, "Planar monopole ultra-wideband antennas with different radiator shapes for 
body-centric wireless networks," in Proceedings of the Progress in Electromagnetics Research Symposium, pp. 839-843, Kuala Lumpur, Malaysia, March 2012.

[20] T. Onishi and S. Uebayashi, "Biological tissue-equivalent phantoms usable in broadband frequency range," NTT DoCOMo Technical Journal, vol. 7, no. 4, 2006.

[21] N. Rishani, M. Al-Husseini, A. El-Hajj, and K. Y. Kabalan, "Dielectric constant determination of an EBG-based wearable antenna," in Proceedings of the Progress in Electromagnetics Research Symposium (PIERS '12), Moscow, Russia, August 2012.

[22] T. Yilmaz and Y. Hao, "Sensing of dielectric property alterations in biological tissues at microwave frequencies," in Proceedings of the 7th Loughborough Antennas and Propagation Conference (LAPC '11), Loughborough, UK, November 2011.

[23] T. Yilmaz and Y. Hao, "Electrical property characterization of blood glucose for on-body sensors," in Proceedings of the 5th European Conference on Antennas and Propagation (EUCAP '11), pp. 3659-3662, Rome, Italy, April 2011.

[24] R. Moro, S. Agneessens, and M. Bozzi, "Wearable textile antenna in substrate integrated waveguide technology," Electronics Letters, vol. 48, no. 16, pp. 985-987, 2012.

[25] D. Lamensdorf and L. Susman, "Baseband-pulse-antenna techniques," IEEE Antennas and Propagation Magazine, vol. 36, no. 1, pp. 20-30, 1994. 

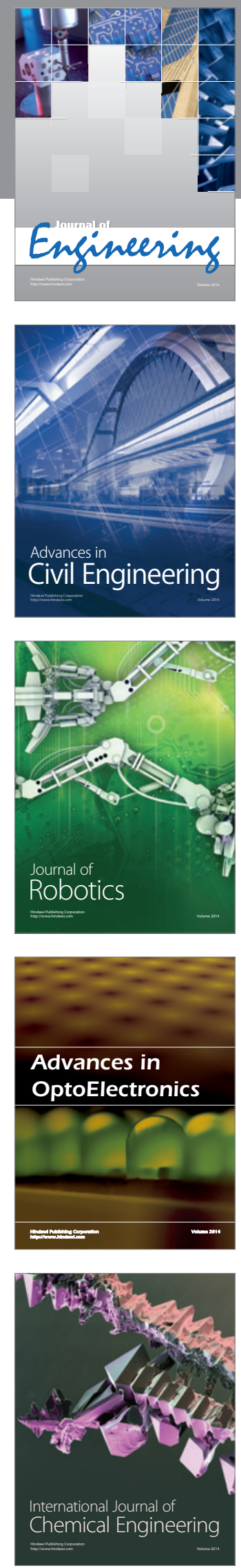

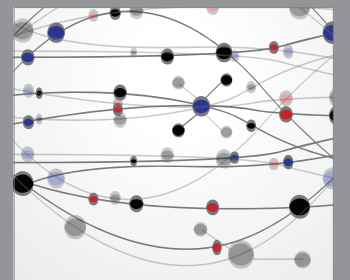

The Scientific World Journal
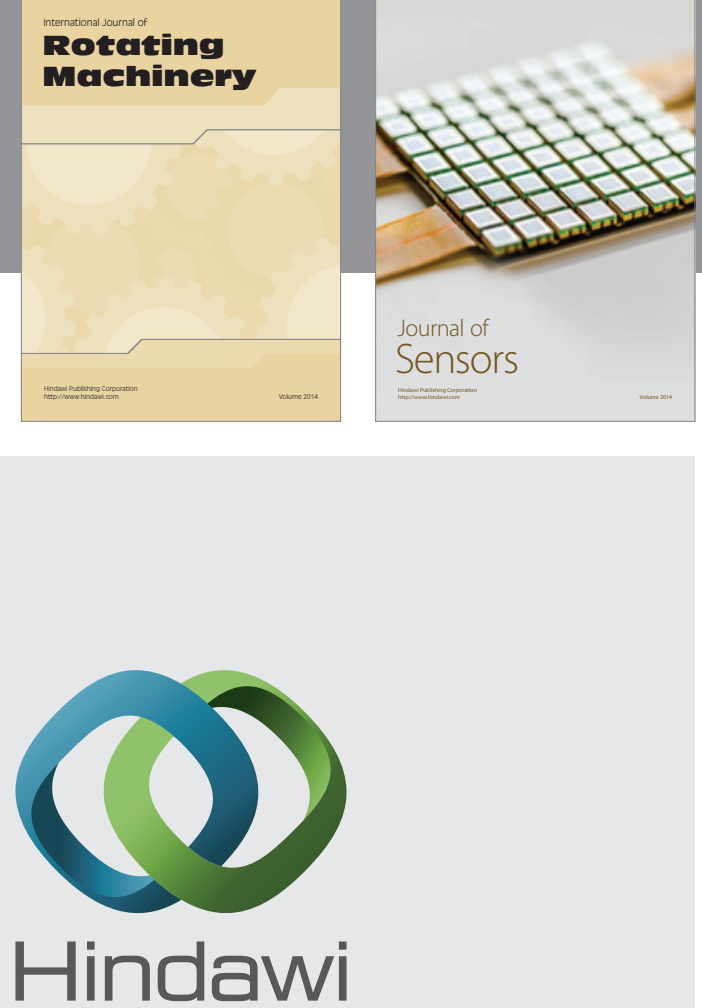

Submit your manuscripts at http://www.hindawi.com
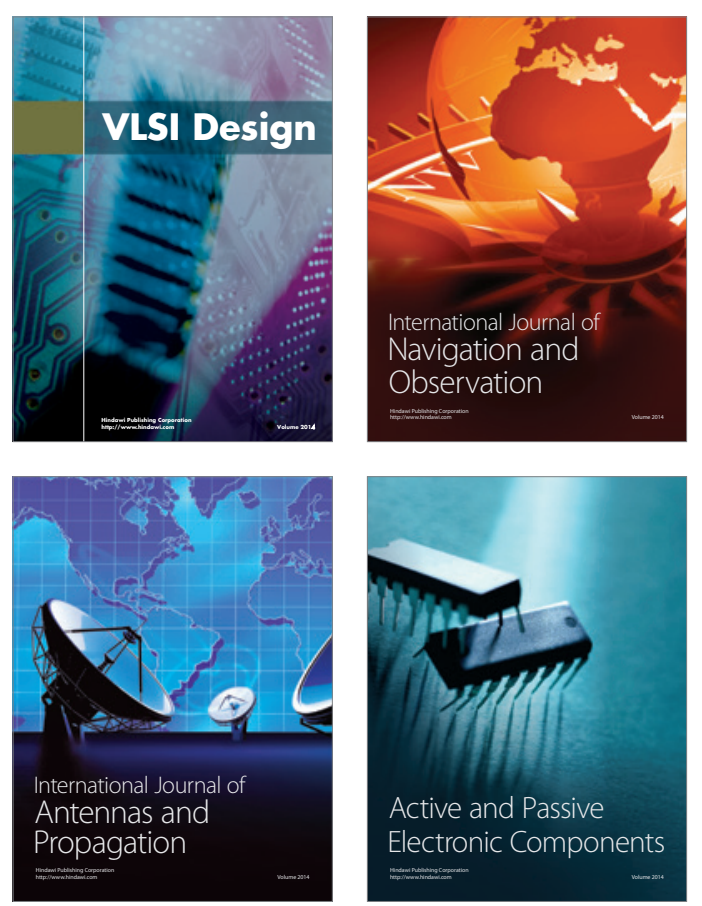
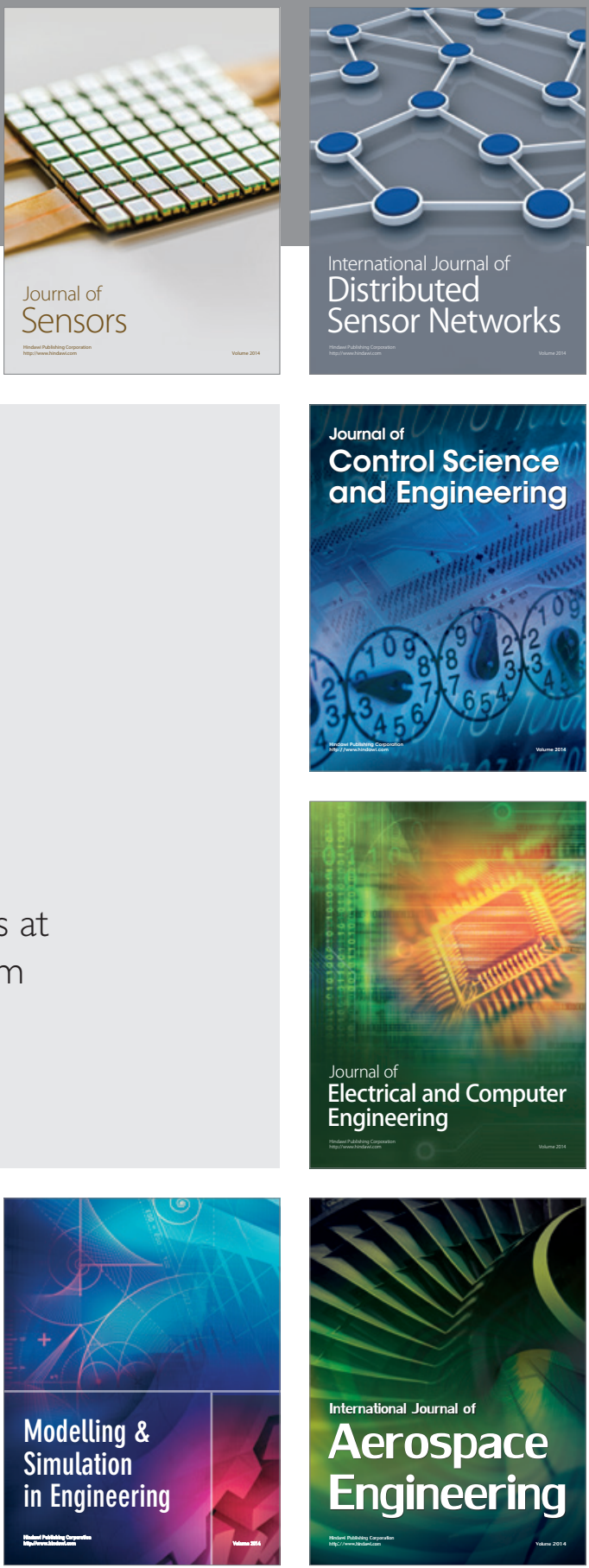

Journal of

Control Science

and Engineering
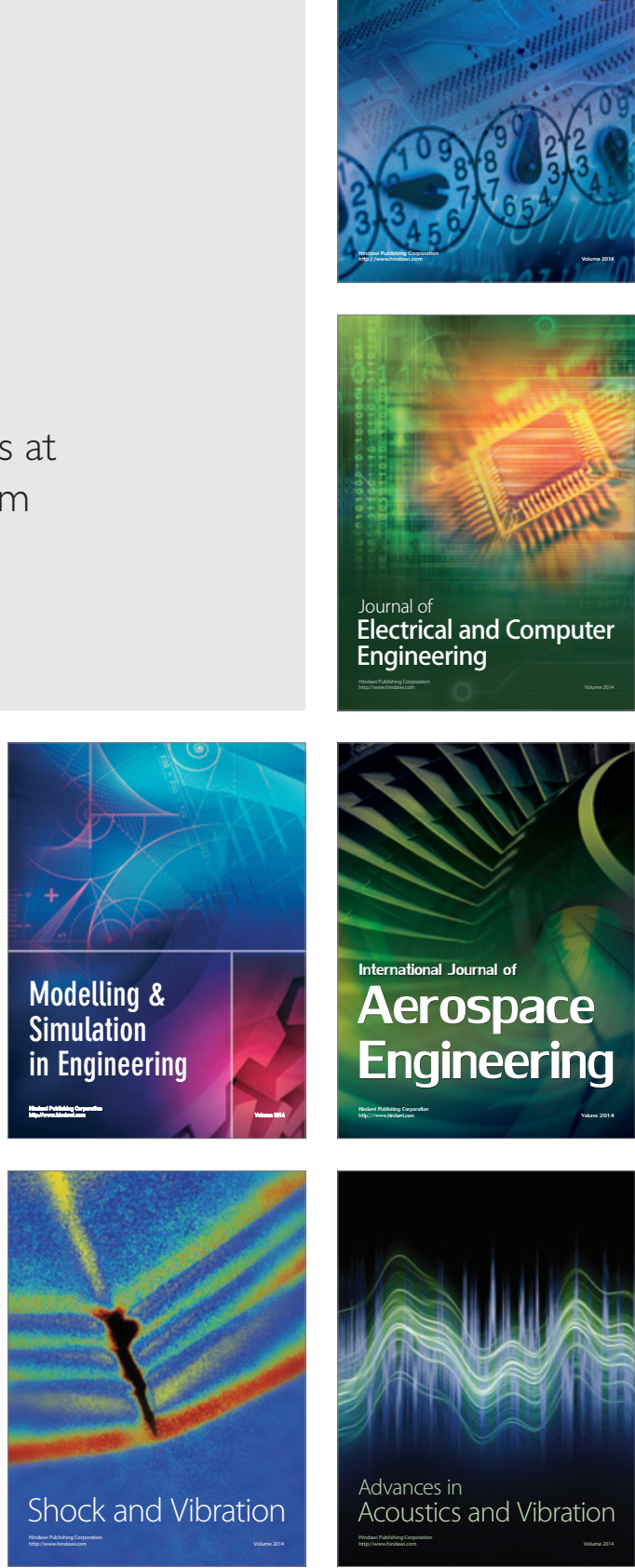